\title{
Analysis of Antimicrobial Medication Consumption in Intensive Care Unit, North West (Tabuk) Region Hospitals, Saudi Arabia
}

\begin{abstract}
Yousef Ahmed Alomi* (iD, The Former General Manager of General Administration of Pharmaceutical Care, Former Head, National Clinical Pharmacy and Pharmacy Practice, Former Head, Pharmacy R\&D Administration, Ministry of Health, Riyadh, SAUDI ARABIA.
\end{abstract}

Abeer Hussin Almasoudi, Director, Administration of Research and Studies, Ministry of Health, Tabuk, SAUDI ARABIA. Ghormallah Abdullah Alghamdi, Consultant Family Medicine, General Manager of Health Affairs in Tabuk Region, Ministry of Health, Tabuk, SAUDI ARABIA.

Samira Ali Asiri, Clinical Pharmacy Staff, Ministry of Health, Riyadh, SAUDI ARABIA.

\section{Correspondence: \\ Yousef Ahmed Alomi, (Bsc. Pharm, MSc. Clin Pharm, BCPS, BCNSP, DiBA, CDE) The Former General Manager of General Administration of Pharmaceutical Care, Former Head, National Clinical pharmacy and Pharmacy Practice, Former Head, Pharmacy R\&D Administration, Ministry of Health, Riyadh, SAUDI ARABIA.}

Phone no: +966 504417712 E-mail:yalomi@gmail.com

Received: 12-01-2019;

Accepted: 29-02-2019

Copyright: $\odot$ the author(s),publisher and licensee Pharmacology, Toxicology and Biomedical Reports. This is an open-access article distributed under the terms of the Creative Commons Attribution NonCommercial License, which permits unrestricted non-commercial use, distribution, and reproduction in any medium, provided the original work is properly cited.

This is an open access article distributed under the terms of the Creative Commons Attribution-NonCommercial-ShareAlike 4.0 License

Access this article online

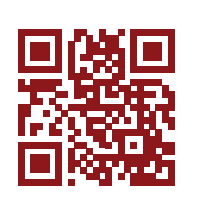

www.ptbreports.org

DOI:

10.5530/PTB.2019.5.22

\begin{abstract}
Objectives: This article describes antimicrobial medication use among different age groups and the cost associated with it in intensive care units at North West (Tabuk) hospitals, Saudi Arabia. The aim of this study to explore the antimicrobial medication use in intensive care units at North West Region Hospitals, Ministry of Health, Saudi Arabia. Methods: It is a 12-month antimicrobial drug use by intensive care units at North West region hospitals which included critical care for adults, pediatrics and neonates. The medications selected by Central Antibiotics committee at $\mathrm{MOH}$ as part of the National Antimicrobial Stewardship program. The consumption was driven from pharmacy database and calculated based on off standard unit of antimicrobials per hospital. The antimicrobials consisted of antibacterial drugs, antifungal and antiviral medications. The cost of antimicrobial consumption was calculated by using the Ministry of Health National Cost database. All cost used were as US currency. Results: The total number of antimicrobial standard units were $(14,305)$ and average $(2,861)$ per hospital. The highest drug consumption was Ceftriaxone $1 \mathrm{gm}$ injection (2724) followed by Imipenem $500 \mathrm{mg}$ injection (1251) and Vancomycin 500 injection (1165). The total cost of Antimicrobial consumption was (53,884.95 USD) and $(10,777$ USD) per each hospital. The highest cost medication consumption from Adults critical care $73.42 \%(39,562.33$ USD) followed by pediatrics critical care $18.15 \%(9,779.93$ USD) and Neonates critical care $8.43 \%(4,542.68$ USD). The highest medication cost was very broad-spectrum antibiotics like Meropenem, Imipenem and Ceftriaxone. It consumed more than $50 \%$ of the cost burden. Conclusion: This study is the first in Saudi Arabia, Gulf and Middle East countries. Health system pharmacist leaders are targeting to implement the antimicrobial stewardship program and National Drug Utilization Evaluation system to control unnecessary medication expenditure and prevent misuse of medicines.

Keyword: Patient, Knowledge, Medications, Ministry of Health, Saudi Arabia.
\end{abstract}

\section{INTRODUCTION}

There are several diseases that have been treated at the critical care department including, but not limited to cardiovascular or respiratory collapse, neurological disorders and infectious diseases. Most medications used in critical care services were antibiotics. The main infectious diseases induced mortality was due to septic shock. The international medical associations have released management guidelines for septic shock periodically. ${ }^{1}$ The most diseases inducing mortality in the Kingdom of Saudi Arabia in the Hajj period were cardiovascular and infectious diseases. ${ }^{2}$ The decision of using an antimicrobial is a challenge, as misuse or unnecessary use of antimicrobials are the major factors underlying the development of multi-drug resistance. ${ }^{3,4}$ The local data showed antibiotic resistance in critical care units. ${ }^{5}$ Antibiotics stewardship program started at the Ministry of Health hospitals about five years ago; however, it was not included in the critical care services. ${ }^{6,7}$ To start the project, it is necessary to know the antibiotic consumption and economic burden on the health care system. ${ }^{8}$ Several studies showed differences in types of antibiotics used in each country. ${ }^{9-13}$ At best to the author's knowledge, there is no study done at KSA or Gulf and Middle East countries about antibiotics consumption in critical care services. The goal of the study is to explore the antibiotics consumption at critical care units in the Northern region (Tabuk) of the
Kingdom of Saudi Arabia.

\section{METHODS}

This study shows a 9-month antimicrobial drug used through critical care units at North West region hospitals which includes all adults, pediatrics and neonatal population. Five hospitals were included included of which hospital 1 has been establish in 1980 to serve 100 beds and its, serves the maternities and pediatrics. Hospital 2 was hospital established in 1990, with the pharmacy care having many departments including, which they are inpatient, outpatient, narcotics, drug information center, clinics and emergency and serve 100 beds also has most specialties (pediatrics, OR, ICU, ER, nursery, AKU, and SW). Hospital 3 build was built up in 1983, which is containing 100 beds, all also all specialties are available except chemotherapeutic department. The pharmacy have several departments, which they are inpatient, outpatient, narcotics and emergency pharmacy. Hospital 4 was started in 1991, the capacity of the hospital is 200 bed, which is the largest in the region and also it does contain verities of specialized and served 7 departments. The pharmacy care units containing five departments which are inpatient, outpatient, narcotics, information center, emergency and clinics department. Hospital 5 hospital was established in 2005 , which is the newest although the pharmacy serves 100 beds with different departments, they are including inpatient, outpatient, information 
centers, narcotics, emergency and clinics, also cover 9 types of wards as the most hospitals in the region. Antibiotics committees were formulated at the above mentioned hospitals through a letter of recommendation which was sent by the General Administration of Pharmaceutical Care at the Ministry of Health for Tabuk Region on October 2013, which stipulates the importance of forming a specialized committee on antibiotics under the supervision and follow up of the department of pharmacy care in the region. Letters of formation of the Antibiotics Committee were sent to all hospitals in Tabuk region in January 2014. In March 2014, this committee was approved by the Director General of Health Affairs in Tabuk Region and guidance to start the application of antibiotics in all hospitals in the region. The actual implementation of the program began in January 2015. The objective of the antibiotic committees was to improve antimicrobial use for hospitalized adults and minimize the emergence and spread of antimicrobial resistance. The objective of the antibiotic committees was to improve antimicrobial use for hospitalized adult and minimizing the emergence and spread of antimicrobial resistance. While the functions of each committees were Supervising the assessment and application of antibiotic strategies in hospitals which are designed by the Antibiotics Committee of the Ministry. Preparation of quarterly reports on the implementation of strategies for the use of antibiotics in hospitals and discussed with the Committee of Pharmacy and therapeutics in the regions. Preparation of bacterial resistance statistics for antibiotics in the area and follow-up and updating. Supervising the training of medical staff (doctors, pharmacists, nurses, specialists, technicians) on the optimal use of antibiotics. Visits to hospitals to ensure the accuracy and validity of the implementation of strategies. Review and analyze indicators of the application of strategies for the use of antibiotics and consider their development in the region of Tabuk. And writing the annual report on the performance, productivity and impact of the program in the region of Tabuk. The antibiotics medications were selected by Central Antibiotics committee at $\mathrm{MOH}$ as part of the National Antimicrobial stewardship program. The consumption is driven from pharmacy database and calculated based on off stranded unit of antimicrobial per hospital. The antimicrobials consisted of antibacterial drugs, antifungal and antiviral medications. The cost of antimicrobial consumption was calculated by using Ministry of Health National Cost database. All cost used was as US currency.

\section{RESULTS}

There were a total of five hospitals with $100-300$ beds that represented $80 \%$ while hospitals with $50-99$ beds that represented $20 \%$. All hospital (100\%) accredited by Saudi Board of Hospital Accreditation (CBAHI) while none $(0 \%)$ of the hospital accredited by International Joint Commissions. The total response month's rate was $68(50.37 \%)$ that included adults' response rate of $31(68.88 \%)$, pediatrics response rate $18(40 \%)$ and neonates response rate $19(42.22 \%)$ (Table 1$)$. The total number of antimicrobial standard units was $(14,305)$ and average $(2,861)$ per hospital. The highest units' consumption at adults' inpatient wards 10,712 (74.88\%) followed by pediatrics wards $2,487(17.39 \%)$ and neonates wards $1,514(10.58 \%)$. The highest drug consumption as general was Ceftriaxone $1 \mathrm{gm}$ injection (2724) followed by Imipenem $500 \mathrm{mg}$ injection (1251) and Vancomycin 500 injection (1165). The highest drug consumption was Ceftriaxone $1 \mathrm{gm}$ injection $(1,918)$ followed by Imipenem + Cilastatin IV $500 \mathrm{mg}(1,043)$ and Vancomycin IV $500 \mathrm{mg}$ (794) at adults' critical care units. The highest drug consumption was Ceftriaxone $1 \mathrm{gm}$ injection (592) followed by Vancomycin IV $500 \mathrm{mg}$ (203) and Gentamicin IV $80 \mathrm{mg}$ (160) at pediatrics' critical care units. The highest drug consumption was Ceftriaxone $1 \mathrm{gm}$ injection (214) followed by Vancomycin IV $500 \mathrm{mg}$ (168) and Levofloxacin IV $500 \mathrm{mg}$ (140) at neonates' critical care units. The total cost of antimicrobial consumption was $(53,884.95$ USD) and (10,777 USD) per hospital. The highest cost medication con- sumption from Adults critical care 73.42\% (39,562.33 USD) followed by pediatrics critical care $18.15 \%$ (9,779.93 USD) and Neonates critical care $8.43 \%$ (4,542.68 USD). The highest drug cost consumption was Meropenem IV $500 \mathrm{mg}$ injection (5,974.08 USD) followed by Ceftriaxone IV $1 \mathrm{~g}(1,419.32 \mathrm{USD})$ and Vancomycin IV $500 \mathrm{mg}$ (1,071.9 USD) at adult's critical care units. The highest drug cost consumption was Meropenem IV $1 \mathrm{~g}$ injection (4,000.50 USD) followed by Meropenem IV $500 \mathrm{mg}$ (1,904.00 USD) and Imipenem + Cilastatin IV $500 \mathrm{mg}$ (1,650.00 USD) at pediatrics' critical care units. The highest drug cost consumption was Levofloxacin IV $500 \mathrm{mg}$ (1,200 USD) followed by Meropenem IV $1 \mathrm{~g}$ (800.10 USD) and Meropenem IV $500 \mathrm{mg}$ (680 USD) at neonates' critical care units. The highest medication cost was for very broad-spectrum antibiotics like Meropenem, Imipenem and Ceftriaxone. It consumed more than $50 \%$ of the cost burden (Table 2).

\section{DISCUSSION}

The prime objective of this study was to determine the level of knowledge regarding antimicrobial medication consumption among study contestants in five major hospitals in Tabuk city. Antimicrobial stewardship programs in hospitals seek to enhance antimicrobial recommending in order to recover individual patient care as well as diminish hospital costs and slow the spread of antimicrobial resistance. These programs emphasis on confirming the proper use of antimicrobials to provide the best patient outcomes, decrease the risk of adverse effects, endorse cost-effectiveness and decrease or steady levels of resistance. The committee needs key performance indicators to measure the improvement and impact of the project. Several key performance indicators founded for instance the resistance pattern of the antibiotic bugs, adherence to antibiotics prescribing guidelines, adherence to monitoring parameters of some antibiotics need drug levels measurement and monitoring and antibiotics consumption. Critical care services presented most of the hospitals in the Northern region in Saudi Arabia. Intensive care is serving medical, surgical and trauma specialties. While there is intensive care in pediatrics and neonatal critical care services existed at several hospitals. The general administration of pharmaceutical care planned to implement antibiotics stewardship program for critical care services for all type of populations. The antibiotics consumption is essential information in demand to measure the clinical and economic impact of the project. This study showed that adult patients consumed a high percentage of antibiotics followed by pediatrics and neonates. The drug consumed most by adults, pediatrics and neonates was parenteral Ceftriaxone and Vancomycin that's similar previous study with utilization of third general cephalosporin. ${ }^{12}$ The specific indication of usage for both antibiotics was not evident in the study and not included in the aim of the study. In neonates, the parenteral Quinolones were highly consumed; however, caused an adverse event to pediatrics less than eighteen years. The study showed that adult patients consumed two thirds of the antibiotics budget. This is expected because of usage of high quantity and expensive medications. The broader spectrum antibiotics Quinolones and a broad spectrum of $\beta$-lactam antibiotics were the highest consumed of all antibiotics in critical care services. The antibiotics stewardship program is essential at all intensive care services in the Northern critical care hospital services and is highly recommended in the Kingdom of Saudi Arabia., ${ }^{74,15}$

\section{CONCLUSION}

The broad-spectrum antibiotics are highly used in the critical care services in the North West region, Saudi Arabia. Annual studies of antibiotics consumption and utilization are highly recommended. The antibiotic stewardship program is required in the kingdom of Saudi Arabia 
Table 1: Hospitals demographic data.

\begin{tabular}{|c|c|c|c|c|c|c|}
\hline & Hospital 1 & Hospital 2 & Hospital 3 & Hospital 4 & Hospital 5 & Total \\
\hline \multicolumn{7}{|l|}{ No of Beds } \\
\hline \multicolumn{7}{|l|}{$<50$} \\
\hline $50-99$ & & & & YES & & $1(20 \%)$ \\
\hline $100-300$ & YES & YES & YES & & YES & $4(80 \%)$ \\
\hline \multicolumn{7}{|l|}{$301-400$} \\
\hline \multicolumn{7}{|l|}{$401-500$} \\
\hline CIBAHI & Yes & Yes & Yes & Yes & Yes & $5(100 \%)$ \\
\hline JCI & No & No & No & No & No & $0(0 \%)$ \\
\hline \multicolumn{7}{|c|}{ Repose Rate } \\
\hline \multicolumn{7}{|l|}{ ICU units } \\
\hline Adults & 9 & 9 & 4 & 0 & 9 & $31(68.88 \%)$ \\
\hline Pediatrics & 0 & 6 & 4 & 0 & 8 & $18(40 \%)$ \\
\hline Neonates & 2 & 4 & 4 & 0 & 9 & $19(42.22 \%)$ \\
\hline Total & 11 & 19 & 12 & 0 & 26 & $68(50.37 \%)$ \\
\hline \multicolumn{7}{|c|}{ Inpatient wards } \\
\hline Adults & 9 & 9 & 4 & 9 & 9 & $40(88.88 \%)$ \\
\hline Pediatrics & 7 & 9 & 4 & 9 & 9 & $38(84.44 \%)$ \\
\hline Neonates & 3 & 9 & 4 & 9 & 7 & $32(71.11 \%)$ \\
\hline Total & 19 & 27 & 12 & 27 & 25 & $110(81.48 \%)$ \\
\hline \multicolumn{7}{|c|}{ OPD clinics } \\
\hline Adults & 9 & 9 & 4 & 0 & 8 & $30(66.66 \%)$ \\
\hline Pediatrics & 6 & 8 & 4 & 1 & 7 & $26(57.77 \%)$ \\
\hline Neonates & 0 & 8 & 4 & 0 & 0 & $12(26.66 \%)$ \\
\hline Total & 15 & 25 & 12 & 1 & 15 & $68(50.37 \%)$ \\
\hline \multicolumn{7}{|l|}{ ER units } \\
\hline Adults & 9 & 5 & 4 & 0 & 0 & $18(40 \%)$ \\
\hline Pediatrics & 0 & 9 & 4 & 9 & 0 & $22(48.88 \%)$ \\
\hline Neonates & 0 & 5 & 4 & 0 & 0 & $9(20 \%)$ \\
\hline Total & 9 & 19 & 12 & 9 & 0 & $49(36.29 \%)$ \\
\hline
\end{tabular}

Table 2: Anti-Microbial drugs consumption at critical care units.

\begin{tabular}{|c|c|c|c|c|c|c|c|c|c|}
\hline $\begin{array}{l}\text { Quantity consumption Anti- } \\
\text { infectious drugs }\end{array}$ & Dosage Forms & Neonates & $\begin{array}{l}\text { Cost } \\
\text { (USD) }\end{array}$ & Pediatrics & $\begin{array}{l}\text { Cost } \\
\text { (USD) }\end{array}$ & Adults & Cost (USD) & $\begin{array}{c}\text { Total } \\
\text { Quantities }\end{array}$ & $\begin{array}{l}\text { Total cost } \\
\text { (USD) }\end{array}$ \\
\hline Cloxacillin sodium IV 250mg & Vial or amp. & 0 & 0.00 & 20 & 7.78 & 6 & 2.334 & 26 & 10.11 \\
\hline Flucloxacillin sodium IV 250mg & Vial or amp. & 20 & 7.78 & 0 & 0.00 & 30 & 11.67 & 50 & 19.45 \\
\hline Piperacillin + Tazobactam IV $2.25 \mathrm{~g}$ & Vial & 62 & 84.32 & 70 & 95.20 & 409 & 556.24 & 541 & 735.76 \\
\hline Piperacillin + Tazobactam IV $4.5 \mathrm{~g}$ & Vial & 20 & 43.73 & 120 & 262.40 & 480 & $1,049.61$ & 620 & $1,355.75$ \\
\hline Ceftazidime IV $1 \mathrm{~g}$ & Vial & 70 & 52.27 & 112 & 83.63 & 572 & 427.11 & 754 & 563.01 \\
\hline Ceftriaxone IV $1 \mathrm{~g}$ & Vial & 214 & 158.36 & 592 & 438.08 & 1918 & $1,419.32$ & 2724 & $2,015.76$ \\
\hline Cefepime IV $1 \mathrm{~g}$ & Vial & 10 & 18.76 & 10 & 18.76 & 129 & 242.004 & 149 & 279.52 \\
\hline Cefepime IV $2 \mathrm{~g}$ & Vial & 40 & 138.67 & 60 & 208.00 & 276 & 956.80 & 376 & $1,303.48$ \\
\hline $\begin{array}{l}\text { Imipenem + Cilastatin IV } \\
500 \mathrm{mg}+500 \mathrm{mg}\end{array}$ & Vial & 58 & 638.00 & 150 & 1650.00 & 1043 & 11473 & 1251 & $13,761.00$ \\
\hline Meropenem IV 500mg & Vial & 50 & 680.00 & 140 & 1904.00 & 606 & 8241.6 & 796 & $10,825.60$ \\
\hline
\end{tabular}




\begin{tabular}{|c|c|c|c|c|c|c|c|c|c|}
\hline Meropenem IV $1 \mathrm{~g}$ & Vial & 30 & 800.10 & 150 & 4000.50 & 224 & $5,974.08$ & 404 & $10,774.68$ \\
\hline Tigecycline IV 50mg & Vial & 0 & 0.00 & 0 & 0.00 & 10 & 500 & 10 & 500.00 \\
\hline Amikacin IV 100mg & Vial or amp. & 76 & 24.62 & 65 & 21.06 & 200 & 64.8 & 341 & 110.48 \\
\hline Amikacin IV 500mg & Vial or amp. & 70 & 31.50 & 100 & 45.00 & 561 & 252.45 & 731 & 328.95 \\
\hline Gentamicin IV 20mg & Vial or amp. & 124 & 74.40 & 146 & 87.60 & 52 & 31.2 & 322 & 193.20 \\
\hline Gentamicin IV 80mg & Vial or amp. & 70 & 42.00 & 160 & 96.00 & 469 & 281.4 & 699 & 419.40 \\
\hline Azithromycin PO 250mg & Tablet & 0 & 0.00 & 40 & 2.88 & 616 & 44.352 & 656 & 47.23 \\
\hline Azithromycin PO 200mg/15ml & Suspension & 82 & 77.89 & 119 & 113.04 & 0 & 0 & 201 & 190.93 \\
\hline Clindamycin IV 300mg & Ampoule & 100 & 173.30 & 90 & 155.97 & 482 & 835.306 & 672 & $1,164.58$ \\
\hline Vancomycin IV 500mg & Vial & 168 & 226.80 & 203 & 274.05 & 794 & $1,071.9$ & 1165 & $1,572.75$ \\
\hline Linezolid PO 600mg & Tablet & 0 & 0.00 & 0 & 0.00 & & 0 & 0 & 0.00 \\
\hline Linezolid IV 600mg & Premixed bag & 0 & 0.00 & 0 & 0.00 & 5 & 1750 & 5 & $1,750.00$ \\
\hline Linezolid PO 100mg & Suspension & 0 & 0.00 & 0 & 0.00 & & 0 & 0 & 0.00 \\
\hline Rifabutine PO 150mg & Tablet & 0 & 0.00 & 0 & 0.00 & 100 & 8.8 & 100 & 8.80 \\
\hline Ciprofloxacin IV 200mg & Bottle & 30 & 22.17 & 20 & 14.78 & 339 & 250.521 & 389 & 287.47 \\
\hline Moxifloxacin IV 400mg & Vial & 0 & 0.00 & 0 & 0.00 & 66 & 2211 & 66 & $2,211.00$ \\
\hline Moxifloxacin PO 400mg & Tablet & 0 & 0.00 & 40 & 45.20 & 154 & 174.02 & 194 & 219.22 \\
\hline Levofloxacin IV 500mg & Premixed bag & 140 & $1,120.00$ & 10 & 80.00 & 90 & 720 & 240 & $1,920.00$ \\
\hline Amphotericin B liposomal 50mg & Vial & 0 & 0.00 & 0 & 0.00 & 0 & 0 & 0 & 0.00 \\
\hline Amphotericin B 50mg & Vial & 0 & 0.00 & 0 & 0.00 & 0 & 0 & 0 & 0.00 \\
\hline Voriconazole IV 200mg & Vial & 0 & 0.00 & 0 & 0.00 & 0 & 0 & 0 & 0.00 \\
\hline Voriconazole PO $200 \mathrm{mg}$ & Tablet & 0 & 0.00 & 0 & 0.00 & 0 & 0 & 0 & 0.00 \\
\hline Caspofungin IV 50mg & Vial & 0 & 0.00 & 0 & 0.00 & 0 & 0 & 0 & 0.00 \\
\hline Micafungin IV $50 \mathrm{mg}$ & Vial & 0 & 0.00 & 0 & 0.00 & 0 & 0 & 0 & 0.00 \\
\hline Acyclovir IV 250mg & Vial & 80 & 128.00 & 110 & 176.00 & 633 & $1,012.8$ & 823 & $1,316.80$ \\
\hline Valaciclovir PO 500mg & Tablet & 0 & 0.00 & 0 & 0.00 & 0 & 0 & 0 & 0.00 \\
\hline Artemisinin PO 250mg & Capsule & 0 & 0.00 & 0 & 0.00 & 0 & 0 & 0 & 0.00 \\
\hline Artesunate PO 50mg & Tablet & 0 & 0.00 & 0 & 0.00 & 0 & 0 & 0 & 0.00 \\
\hline Artesunate IV 60mg & Ampoule & 0 & 0.00 & 0 & 0.00 & 0 & 0 & 0 & 0.00 \\
\hline Proguanil PO 100mg & Tablet & 0 & 0.00 & 0 & 0.00 & 0 & 0 & 0 & 0.00 \\
\hline $\begin{array}{l}\text { Artemether +Lumefantrine PO } \\
\text { 20/120mg }\end{array}$ & Tablet & 0 & 0.00 & 0 & 0.00 & 0 & 0 & 0 & 0.00 \\
\hline Artmether IV $20 \mathrm{mg}$ & Ampoule & 0 & 0.00 & 0 & 0.00 & 0 & 0 & 0 & 0.00 \\
\hline
\end{tabular}

\section{ACKNOWLEDGEMENT}

None.

\section{CONFLICT OF INTEREST}

The authors declare no conflict of interest.

\section{ABBREVIATIONS}

ER: Emergency; KSA: Kingdom of Saudi Arabia; MOH: Ministry of Health; OR: Operation; ICU: Intensive Care Unit; AKU: Artificial Kidney Unit; SW: Surgical Wards; UDS: Unite State Dollars.

\section{ORCID ID}

Yousef Ahmed Alomi (iD https://orcid.org/0000-0003-1381-628X

\section{REFERENCES}

1. Rhodes A. Surviving Sepsis Campaign: International Guidelines for Management of Sepsis and Septic Shock: 2016. Ctitical Care Med. 2017;45(3):486-552.

2. Alomi YA, Alhennawi K, Khayayt N. Clinical Pharmacy Services and Workforce Requirements at MOH Hospitals during Ten years Mass Gathering Haij ( 20062015 ) in Makkah and Al-Madina Regions, Saudi Arabia. Journal of Pharmacy Practice and Community Medicine. 2017;3(4):S48-55.

3. Alawi MM, Darwesh BM. A stepwise introduction of a successful antimicrobial stewardship program. Saudi Med J. 2016;37(12):1350-8.

4. Aref ABA, Mohamad AA, Mohammed AA, et al. Non prescribed sale of antibiotics in Riyadh, Saudi Arabia: A Cross Sectional Study. Clin Microbiol Infect. 2016;2(1):561.e7-19.

5. AlYousef SA. Surveillance of antibiotic-resistant bacteria in King Khalid hospital, Hafr Al-Batin, Saudi Arabia, during 2013. Jundishapur J Microbiol. 2016;9(9):e19552.

6. Alomi YA. National Antimicrobial Stewardship Program in Saudi Arabia; Initiative and the Future. Open Access J Surg. 2017;4(5):1-7

7. Lanckohr C. Antibiotic stewardship - also in the intensive care unit?. Antibio Steward - Auch auf der Intensivstation?. 2016;21(2):95-9. 
8. Lee CF, Cowling BJ, Feng S, Aso H, Wu P, Fukuda K, et al. Impact of antibiotic stewardship programmes in Asia: A systematic review and meta-analysis. $J$ Antimicrob Chemother. 2018;73(4):844-51.

9. European Centre for Disease Prevention and Control. Antimicrobial consumption 2016. Annual epidemiological report for 2016. 2018. Available from: https://ecdc. europa.eu/sites/portal/files/documents/AER_for_2016-AMC.pdf.

10. European Centre for Disease Prevention and Control. Antimicrobial consumption 2015. Annual epidemiological report for 2015. 2018. Available from: https://ecdc. europa.eu/sites/portal/files/documents/AER_for_2015-HIV-AIDS.pdf.

11. Al-Tawfiq JA. Changes in the pattern of hospital intravenous antimicrobial use in Saudi Arabia, 2006-2008. Ann Saudi Med. 2012;32(5):517-20.
12. Axente C, Licker M, Moldovan R, Hogea E, Muntean D, Horhat F, et al. Antimicrobial consumption, costs and resistance patterns: A two year prospective study in a Romanian intensive care unit. BMC Infect Dis. 2017;17(1):1-9.

13. Bozkurt F, Kaya S, Tekin R, Gulsun S, Deveci O, Dayan S, et al. Analysis of antimicrobial consumption and cost in a teaching hospital. J Infect Public Health. 2014:7(2):161-9.

14. Kaki R, Elligsen M, Walker S, Simor A, Palmay L, Daneman N. Impact of antimicrobial stewardship in critical care: A systematic review. J Antimicrob Chemother. 2011;66(6):1223-30.

15. Enani MA. The antimicrobial stewardship program in Gulf Cooperation Council (GCC) states: Insights from a regional survey. J Infect Prev. 2016;17(1):16-20. 